\title{
Glade cascades: indirect legacy effects of pastoralism enhance the abundance and spatial structuring of arboreal fauna
}

\author{
Colin M. Donihue, ${ }^{1,2,5}$ Lauren M. Porensky, ${ }^{2,3}$ Johannes Foufopoulos, ${ }^{1}$ Corinna Riginos, ${ }^{2,4}$ \\ And Robert M. Pringle 2,4 \\ ${ }^{1}$ School of Natural Resources and the Environment, University of Michigan, Ann Arbor, Michigan 48109 USA \\ ${ }^{2}$ Mpala Research Centre, Box 555, Nanyuki 10400 Kenya \\ ${ }^{3}$ Department of Plant Sciences, University of California, Davis, California 95616 USA \\ ${ }^{4}$ Department of Ecology and Evolutionary Biology, Princeton University, Princeton, New Jersey 08544 USA
}

\begin{abstract}
Studies in community ecology are typically conducted over the span of a few years, and results are often interpreted as the product of contemporary processes and interactions. All landscapes have histories, however, and observed patterns of distribution and abundance frequently reflect enduring legacies of past ecological events, the existence and influence of which may not be obvious to investigators. In East Africa, most wildlife occurs outside national reserves and often coexists there with livestock, which are traditionally corralled at night in temporary thorn fence enclosures, or bomas. After being abandoned, bomas develop into nutrient-rich, treeless glades that can persist for more than a century. These hotspots of primary productivity attract both native and domestic large herbivores, but the extent to which their effects cascade to other consumers is unknown. Here, we document positive edge effects of glades on the mean size and growth rates of Acacia trees and show that the density and biomass of arboreal geckos (Lygodactylus keniensis) are elevated near glades and decrease with distance from glades. The edge response of geckos is an indirect effect arising from the positive influence of glades on arboreal arthropod biomass (a trophic effect) and average tree size (a non-trophic effect). By clearing plots of trees to simulate glades, we experimentally demonstrate that these legacy effects arise from the elevated nutrient content of glades as opposed to their distinctive structural features. Finally, we investigated interactions among glade edges, showing that legacy effects are dampened (rather than enhanced) by the presence of other glades nearby. Collectively, our results show that legacy effects of traditional pastoral practices cascade into the treetops, imparting spatial structure across multiple trophic levels in an otherwise homogeneous Kenyan savanna ecosystem.
\end{abstract}

Key words: Acacia; bomas; cattle; dwarf gecko; edge effects; glades; grazing lawns; kraals; Laikipia, Kenya; livestock herding; Lygodactylus keniensis; pastoralism.

\section{INTRODUCTION}

Legacy effects occur when the influence of an ecological process or interaction persists long after the process or interaction has ceased. Such effects are hypothesized to be a key feature of couplings between human and natural systems (Liu et al. 2007). Even while their importance is frequently invoked, legacy effects are rarely studied directly. This is because most field studies are conducted over short periods of several months to several years without the benefit of detailed landscape histories. Thus, many legacy effects go unidentified, are treated as unexplained variation, or are incorrectly attributed to contemporary processes. When they have been identified, however, legacy effects have been shown

Manuscript received 24 May 2012; revised 30 October 2012; accepted 21 November 2012. Corresponding Editor: L. A. Dyer.

5 Present address: School of Forestry and Environmental Studies, Greeley Hall, 370 Prospect Street, Yale University, New Haven, Connecticut 06511 USA.

E-mail: colin.donihue@yale.edu to be important determinants of community composition and trophic interactions (Foster et al. 2003, Ledger et al. 2006, Rowe 2007, Huntzinger et al. 2011, Nuttle et al. 2011). Well-known examples come from ecosystem ecology and forestry, where present-day patterns of succession and nutrient dynamics can often be traced to lingering influences of fire (Figueroa-Rangel et al. 2008), invasions (Elgersma et al. 2011), logging (Friedman and Reich 2005), and agricultural land use (Dwyer et al. 2010, McKey et al. 2010).

Livestock are often maintained at high densities, which make them good candidates for shaping landscape histories that produce legacy effects at the community level. For example, intensive grazing by domestic ungulates can cause soil compaction and erosion, which can in turn produce shifts in the species composition of plants and animals and potentially lead to alternative stable states (Valone et al. 2002, Sharp and Whittaker 2003).

There also exists potential for subtler, yet biologically important, legacies of pastoral and ranching practices. 
For centuries, pastoralists throughout eastern and southern Africa have enclosed livestock nightly within bomas (temporary corrals) for protection (Western and Dunne 1979, Lamprey and Reid 2004). In central Kenya, abandoned bomas are colonized by grasses, creating nutrient-rich, treeless "glades" with elevated primary production (Young et al. 1995, Augustine and McNaughton 2004a, Veblen 2012). Glades can persist for more than a century, especially when large, wild ungulates perpetuate differential nutrient concentrations by preferentially foraging in and around glades (Augustine and McNaughton 2004a, Veblen and Young 2010). Ungulates can suppress woody encroachment directly via browsing and indirectly by mediating competition between woody and herbaceous vegetation (Augustine and McNaughton 2004b, Porensky and Veblen 2012).

Glades have edge effects that can extend more than 50 $\mathrm{m}$ into the surrounding savanna matrix (Young et al. 1995, Muchiru et al. 2009, Porensky 2011, Veblen 2012). Relative to the background savanna, glade edges exhibit greater large-herbivore utilization, greater understory plant cover and biomass, reduced understory plant diversity, more large trees ( $>4 \mathrm{~m}$ tall), and different soil properties (Young et al. 1995, Muchiru et al. 2009, Porensky 2011, Veblen 2012). The extent to which tree productivity and small-animal communities respond to these distinctive and ecologically significant glade edge patterns remains unclear.

Recent work suggests that glade edge effects can be altered by the presence of other, nearby glades (Porensky 2011). Relative to isolated glade edges, areas located between nearby glades exhibit lower largeherbivore use, higher densities of small trees $(<2 \mathrm{~m}$ tall), and lower cover of glade specialist plant species. Interactions between nearby glade edges are likely driven by a combination of legacy effects and feedbacks. While bomas are active, areas between nearby bomas experience especially intensive cattle use, low browser density, and low grass cover. This combination likely contributes to a pulse of sapling establishment. By reducing visibility, small trees are likely to deter midsized wildlife, which would otherwise browse in and fertilize glade edges (Riginos and Grace 2008). Thus, whereas isolated glade edges are associated with high grass cover and high wildlife use, interacting glade edges are associated with high tree cover and low wildlife use. Again, it is unclear whether or how these edge interactions impact other community properties, such as small-animal abundance.

Here, we examined the effects of glade edges and edge-edge interactions on the productivity and size structure of Acacia trees, as well as patterns of abundance in an arboreal animal community comprising insects, spiders, and a common diurnal gecko (Lygodactylus keniensis). Specifically, we tested three hypotheses suggested by prior work. (1) The highly productive conditions associated with glades should lead to elevated abundance and biomass of arboreal insects and preda- tors in glade edges, as observed around nutrient-rich termite mounds in the same system (Pringle et al. 2010). (2) These patterns are driven by resource availability (Pringle et al. 2010) and therefore should not be observed near treeless areas that are structurally similar to glades but lack the high nutrient concentrations. (3) The predicted positive edge effects of glades on consumer abundance should be muted, not amplified, by the presence of nearby glades due to edge-edge interactions (Porensky 2011).

\section{Methods}

\section{Study system}

Our research was conducted at the Mpala Research Centre in the Laikipia County of Kenya $\left(0^{\circ} 17^{\prime} 27^{\prime \prime} \mathrm{N}\right.$, $\left.36^{\circ} 53^{\prime} 37^{\prime \prime} \mathrm{E}\right)$. The black-cotton vertisol soils of our study site exhibit high clay content (45-60\%) and impeded drainage (Ahn and Geiger 1987) and occur in many parts of eastern Africa. At Mpala, five grass species and two forbs account for $>90 \%$ of understory cover (Young et al. 1998), and the woody-plant community consists almost exclusively of the myrmecophytic tree Acacia drepanolobium ( $>97 \%$ cover; Young et al. 1997). Four symbiotic ant species inhabit $A$. drepanolobium at this site: Crematogaster sjostedti, $C$. mimosae, $C$. nigriceps, and Tetraponera penzigi; these ants significantly impact the life history of $A$. drepanolobium (Palmer et al. 2008, 2010) and its interactions with vertebrate and invertebrate herbivores (Kuria 2006, Goheen and Palmer 2010).

Our primary study organism was the dwarf gecko Lygodactylus keniensis Parker, a small (3-4 cm snoutvent length) arboreal lizard (Greer 1967). This species is the most abundant vertebrate in the system, with local densities varying from 100-1000 per hectare (Pringle et al. 2007). This patchiness is caused in part by ungulate herbivores, which generally suppress gecko abundance (Pringle et al. 2007), and by elephants (Pringle 2008) and termite mounds (Pringle et al. 2010), which increase gecko abundance at different scales. Geckos prey upon insects 3-25 $\mathrm{mm}$ in length, but do not consume Acacia ants (Greer 1967). Stable-isotope analyses have shown that the invertebrates and geckos inhabiting $A$. drepanolobium canopies derive their energy fundamentally from $\mathrm{C}_{3}$ trees with minimal energetic input from $\mathrm{C}_{4}$ grasses (Pringle and Fox-Dobbs 2008); we believe that this justifies our approach of analyzing this assemblage as a single subcommunity.

Glades at Mpala range from $50-100 \mathrm{~m}$ in diameter (2000-8000 $\mathrm{m}^{2}$ ) and are dominated (depending on age) by the grasses Cynodon plectostachyus (an early colonizer) and Pennisetum stramineum (a later-successional species; Young et al. 1995, Veblen 2008, 2012). Glades are irregularly distributed across the study site, with high variability in inter-glade distance (Porensky 2011). All glades used in this study were at least 50 years old (Veblen 2012). 


\section{Study design}

We used repeated surveys to quantify legacy effects radiating from glade edges across several trophic levels. Surveys were conducted along $6 \mathrm{~m}$ wide belt transects falling into four treatment groups. "Isolated-glade transects" (two at each of four separate glades), designed to examine simple edge effects, extended $100 \mathrm{~m}$ in randomly chosen directions from glades that were $\geq 250$ $\mathrm{m}$ from any other glade. For all analyses, data from the two transects surveyed at each isolated glade were treated as subsamples ( $n=4$ isolated glades) to avoid pseudoreplication. "Multiple-glade transects" $(n=3)$, designed to examine edge-edge interactions, stretched between two nearby glades (105-135 $\mathrm{m}$ apart from edge to edge). "Control transects" $(n=4)$, designed to provide a baseline for reference, were $100 \mathrm{~m}$ long and located $\geq 300 \mathrm{~m}$ from the nearest glade. (For further information on the glade and control areas used in this study, see Porensky [2011] and Porensky and Veblen [2012].) Lastly, "cleared-plot transects" $(n=3)$, designed to differentiate the effects of two key attributes of glades (elevated nutrient concentrations and treelessness), extended $100 \mathrm{~m}$ in randomly chosen directions from experimental plots in which all trees had been removed. These cleared plots were created in 2006 by cutting trees and painting the stumps with undiluted picloram herbicide, resulting in $\sim 100 \%$ mortality without directly affecting grass. Cleared plots $(\sim 36-\mathrm{m}$ radius $)$ were similar in size to focal glades $(36 \pm 6 \mathrm{~m})$, and, like glades, are heavily utilized by ungulate herbivores (C. Riginos, unpublished manuscript). All transects were grouped into three blocks along a north-south axis.

\section{Data collection}

In June 2010, we tagged all trees $>1 \mathrm{~m}$ tall in each transect ( $n=376,226,225$, and 101 for isolated- and multiple-glade, control, and cleared-plot transects, respectively) and recorded tree height, basal circumference at $15 \mathrm{~cm}$, resident ant species, and distance to the nearest termite mound. Geckos rarely inhabit trees $<1$ $\mathrm{m}$ tall. We quantified tree surface area by estimating the surface area of the main stem as if it were a cylinder (Pringle et al. 2010), which provides a better predictor of gecko presence/absence than height or diameter independently (although height explained $82 \%$ of the variance in surface area in the present dataset). Tree growth rates were measured by affixing two plastic cable ties $15 \mathrm{~cm}$ from the tips of two randomly selected branches on $\sim 10$ randomly selected trees per transect ( $n$ $=145$ total) and in August 2010, measuring total growth of each branch over the preceding two months.

Once per month from June-August 2010, we exhaustively searched every tree and recorded the number of male, female, and subadult geckos (see Pringle et al. 2010 for methodological details). Gecko biomass was estimated using the average body mass of 125 males, 96 females, and 56 subadults captured from 2006 to 2008 (R. M. Pringle, unpublished data). Although we did not mark individuals for density estimation, prior work shows that the observed number of geckos in surveys is an excellent proxy for densities estimated using markresight approaches. Pringle et al. (2007) estimated gecko densities using mark-resight methods in three successive surveys of 625 - and $2500-\mathrm{m}^{2}$ plots and found that the average observed number of geckos per survey explained $>83 \%$ of the variance in estimated density (given by the linear formula: density $=0.003+1.74 \times$ [average observed number of individuals per survey/unit area]). Here, we primarily report and model per-tree gecko abundance; however, we also calculated a minimum gecko density based on the average observed number of geckos per square meter, knowing that this metric is highly correlated with mark-resight density estimation.

Edge effects in the arboreal insect community were assessed on $\sim 10$ randomly selected trees (all $\sim 2 \mathrm{~m}$ tall, $n$ $=49$ total) at varying distances from each of four isolated glades (the trees were located well away from those used to assess gecko abundance). A plastic sheet was placed beneath each tree, and we applied $\sim 400 \mathrm{~mL}$ of insecticide (alphacypermerthrin, diluted 0.05:1 in water) to each tree with a knapsack sprayer (Kuria et al. 2010). We then collected all non-ant invertebrates falling onto the sheet during the subsequent $30 \mathrm{~min}$. For each sampled tree, we recorded height, basal circumference, resident ant species, and distance from glade. Specimens were counted, identified to order, dried, and weighed.

We also sampled flying insects using sticky traps, to complement insecticide misting and capture insects that might fly away from a tree during insecticide application. We established new 90-m transects at each of the four isolated glades used for gecko surveys, three cleared plots, and four control sites (but not at multiple-glade sites). For glades and cleared plots, this transect extended away from the glade/plot in a randomly chosen direction (different than the direction used for gecko and tree growth surveys, and $\geq 20 \mathrm{~m}$ from these transects). Traps were made from Tanglefoot Insect Barriers (Contech Enterprises, Victoria, British Colombia, Canada) placed on index cards (blue, yellow, green, red; $7.5 \times 12.5 \mathrm{~cm}$ ). We hung four traps (one of each color) $1.5 \mathrm{~m}$ high on trees located $0,30,60$, and $90 \mathrm{~m}$ from the starting point of the transect (corresponding to edges for glades and plots; arbitrary for controls). Traps were collected after $72 \mathrm{~h}$, and all insects were counted and identified to order. At each distance along each transect, results were averaged across the four traps.

\section{Statistical analyses}

Edge effect depth, magnitude, and direction.-Descriptive statistics are given as means \pm SE. Three response variables (tree size, gecko abundance, and gecko biomass) had data with high replication and spatial resolution. For these variables, we determined edge effect depths using nonlinear regression and jackknifing (details in Porensky 2011). Briefly, we modeled edge 
TABLE 1. Response values (mean $\pm \mathrm{SE}$ ) for depths of edge effects on Acacia trees and arboreal geckos (Lygodactylus keniensis).

\begin{tabular}{lccc}
\hline \hline \multicolumn{1}{c}{ Response variable } & $\begin{array}{c}\text { Isolated-glade edge depth } \\
(\mathrm{m}, n=4)\end{array}$ & $\begin{array}{c}\text { Multiple-glade edge depth } \\
(\mathrm{m}, n=3)\end{array}$ & $\begin{array}{c}\text { All-glades edge depth } \\
(\mathrm{m}, n=7)\end{array}$ \\
\hline Tree surface area $\left(\mathrm{m}^{2}\right)$ & $10 \pm 1$ & $9 \pm 7$ & $0 \pm 0$ \\
Gecko density (no. geckos/tree) & $20 \pm 16$ & $1 \pm 1$ & $15 \pm 9$ \\
Gecko biomass (g/tree) & $29 \pm 15$ & $17 \pm 6$ & $38 \pm 11$ \\
\hline
\end{tabular}

Notes: Edge depth was defined as the distance from the glade edge at which the average fitted model's confidence interval no longer diverged from the reference confidence interval. Jackknifing was used to estimate uncertainty. Isolated glades were $>250 \mathrm{~m}$ and non-isolated glades were $<150 \mathrm{~m}$ from a second glade.

effects for each response using the following nonlinear equation, which includes linear, sigmoid, and unimodal edge effect shape components as follows:

$$
y=a+b x+\frac{b_{1}}{1+e^{\left(b_{2}-X\right) \times b_{3}}}+h \times \exp \left[-\left(X-X_{0}\right)^{2} / 2 W^{2}\right]
$$

where $X$ is the distance from glade, and the other variables are fitted constants. For each response variable along each transect, we fit the model using the nonlinear platform in JMP version 8.0 (SAS Institute 2009) and an expectation-maximization approach. We then averaged the fitted models and generated $90 \%$ confidence intervals. Finally, we used non-glade (control and clearedplot) transects $(n=7)$ to generate a $90 \%$ "reference confidence interval." We defined edge depth as the distance from glade beyond which the confidence intervals for the average model and the reference always overlapped. We used jackknifing to estimate edge depth mean and variance. For each of the three response variables, we calculated an edge depth value for all glades combined $(n=7)$, then calculated edge depths separately for isolated glades $(n=4)$ and multiple glades $(n=3)$.

This nonlinear regression and model-averaging approach avoids problems arising from spatial autocorrelation of trees within each transect, but it requires a large amount of data with high spatial resolution. Arborealarthropod abundance could not be sampled so intensively because of the effort and pesticide use required. We therefore analyzed effects of glade proximity on arboreal arthropods differently, using a mixed model with a random effect denoting transect identity. (Because there were $<10$ trees from any given transect in this data set, we do not expect substantive biases from autocorrelation.) We used this model to plot conditional predictions of arthropod abundance (which include random-effect estimates) for each distance from isolated glades.

To determine edge effect magnitudes and to compare them across treatments, we developed a method that could be used for all response variables, regardless of sampling resolution. Using results from the edge depth analyses, we identified a maximum distance at which response variables were likely to be affected by glade presence; to be conservative, we set this maximum distance $=49 \mathrm{~m}$, corresponding to the largest calculated edge depth $(38 \mathrm{~m})$ plus one standard error $(11 \mathrm{~m}$; see Table 1). For each response variable along each transect, we calculated a mean "glade edge" value by averaging all data collected at distances $<49 \mathrm{~m}$ from the start of the transect. We then calculated a "far-from-glade" value by averaging all data collected at distances $>49 \mathrm{~m}$. This process yielded two values of each response variable per transect. We compared "glade edge" and "far-from-glade" values using paired $t$ tests to test whether significant edge effects were observed for each response variable.

Treatment effects.-To assess treatment effects, we used ANOVA and Tukey's honestly significant difference (HSD) post hoc means comparison tests to compare "glade edge" values (i.e., the average of all data collected $<49 \mathrm{~m}$ from the nearest glade, clearedplot, or control transect starting point) among treatments. We first compared all glade (isolated and multiple) against all non-glade (control and clearedplot) transects. We then compared values across all four transect types (i.e., control vs. cleared plot vs. isolated glade vs. multiple glade). Identical methods were used to compare "far-from-glade" values (averages of data collected in the $>49-\mathrm{m}$ zone of each transect) among treatments. Data were transformed when necessary to meet assumptions of ANOVA. In all cases, model residuals met assumptions of normality (Shapiro-Wilk tests) and homoscedasticity (Levene's tests). Block was removed from models in which it was not significant.

Determinants of per-tree gecko abundance.-At the scale of individual trees, we calculated the average number of geckos on each tree over the three surveys of the four isolated-glade transects, rounded to the nearest integer, and used the trees as the units of analysis. We followed Pringle et al. (2010) in modeling mean per-tree gecko abundance as an ordinal response (taking values of $0,1,2$, or $\geq 3$ ) and analyzed these data using ordinallogistic regression. Guided by earlier work, we chose five predictor variables a priori and constructed candidate sets of 32 ordinal regression models using all combinations of these variables: square-root transformed tree size, log-transformed distance to nearest glade, resident symbiotic ant, block location, and proximity to termite mound (an ordinal variable with five categories: $0-5 \mathrm{~m}$, 5-10 m, . , > $>20 \mathrm{~m}$ ). Because we did not have a priori hypotheses about the biological effects of interactions 

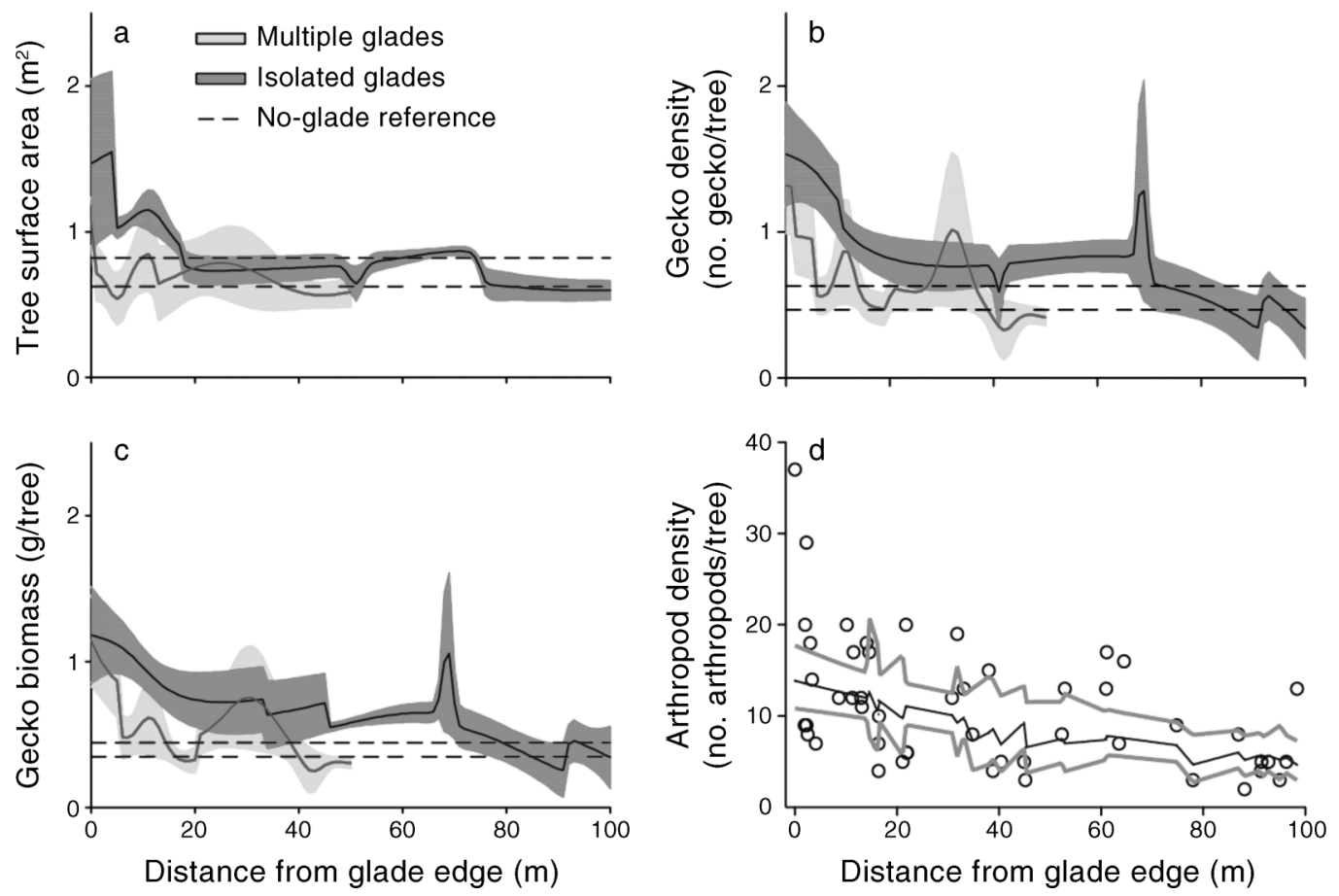

FIG. 1. (a-c) Fitted nonlinear models (mean $\pm \mathrm{SE}$ ) for average Acacia tree surface area, gecko (Lygodactylus keniensis) abundance per tree, and gecko biomass per tree along isolated-glade and multiple-glade transects. No-glade reference intervals are based on data from cleared-plot and control transects $(n=7)$. (d) Scatterplot of total arthropod abundance per tree as a function of distance from isolated glades only, with lines showing predicted values (thin black line) and 95\% CIs (thick gray lines) from a mixed-model regression with log-transformed distance term and random effect of transect identity.

between these variables, we did not include interaction terms in the models. Models were ranked using the second-order Akaike information criterion $\left(\mathrm{AIC}_{\mathrm{c}}\right.$; Burnham and Anderson 2010). To assess goodness-of-fit, we used our top-ranked model to generate the expected number of geckos on each tree; we then binned the trees for each transect in $10-\mathrm{m}$ subsections, calculated the mean predicted number of geckos in each 10-m bin, and plotted these mean predicted values against the mean observed values for the same trees. To further test our highest ranking model, we repeated this procedure using observed values from a novel dataset collected in April 2011 (nine months after the surveys used to parameterize the models). The novel data were collected using identical survey methods for 236 total trees distributed across six 100-m isolated-glade transects. All analyses were conducted using JMP version 8.0 (SAS Institute 2009).

\section{Results}

In total, we surveyed 928 unique trees, sampled 2096 unique arthropods (1553 using sticky traps and 543 using insecticidal mist), and recorded 1687 gecko observations.

\section{Edge effects within treatments}

We determined edge effect depths after fitting nonlinear regression models to tree size and per-tree gecko abundance and biomass (Fig. 1a-c). Depths varied from $0 \mathrm{~m}$ for tree size to $38 \pm 11 \mathrm{~m}$ for gecko biomass (Table 1). We therefore used the conservative value of $49 \mathrm{~m}$ to define edge depth for subsequent analyses. Total arthropod abundance (log-transformed) declined significantly with increasing distance from isolated glades $\left(r^{2}=0.34, F_{1,19.2}=7.5, P=0.01\right.$; Fig. 1d), although we could not calculate edge depth for this variable (see Methods).

For isolated-glade transects $(n=4)$, mean tree size was $24 \%$ greater in glade edges $\left(<49 \mathrm{~m}, 0.87 \pm 0.07 \mathrm{~m}^{2}\right)$ than far from glades $\left(>49 \mathrm{~m}, 0.70 \pm 0.04 \mathrm{~m}^{2}\right.$; paired $t=$ $-4.23, P=0.02$; Fig. 2). To contextualize this result, data from Pringle et al. (2007) showed that gecko density increased significantly as a linear function of mean tree height in plots, with a $24 \%$ increase in mean tree height generating an expected $20-23 \%$ increase in gecko density across the range of tree sizes that occur in this blackcotton soil system. In contrast to mean tree size, the density of trees $(>1 \mathrm{~m}$ tall $)$ in glade edges $(0.15 \pm 0.03$ trees $/ \mathrm{m}^{2}$ ) was indistinguishable from that far from glades $\left(0.16 \pm 0.03\right.$ trees $/ \mathrm{m}^{2}$; paired $t=0.66, P=0.6$; Fig. 2). Mean total arthropod biomass per tree was more than three times greater in isolated-glade edges $(0.22 \pm$ $0.055 \mathrm{~g})$ than far from glades $(0.069 \pm 0.022 \mathrm{~g}$; paired $t=$ $-3.52, P=0.04$; Fig. 2). Finally, mean abundance and biomass of geckos per tree were both $50 \%$ greater in isolated-glade edges than far from glades $(0.95 \pm 0.16$ 


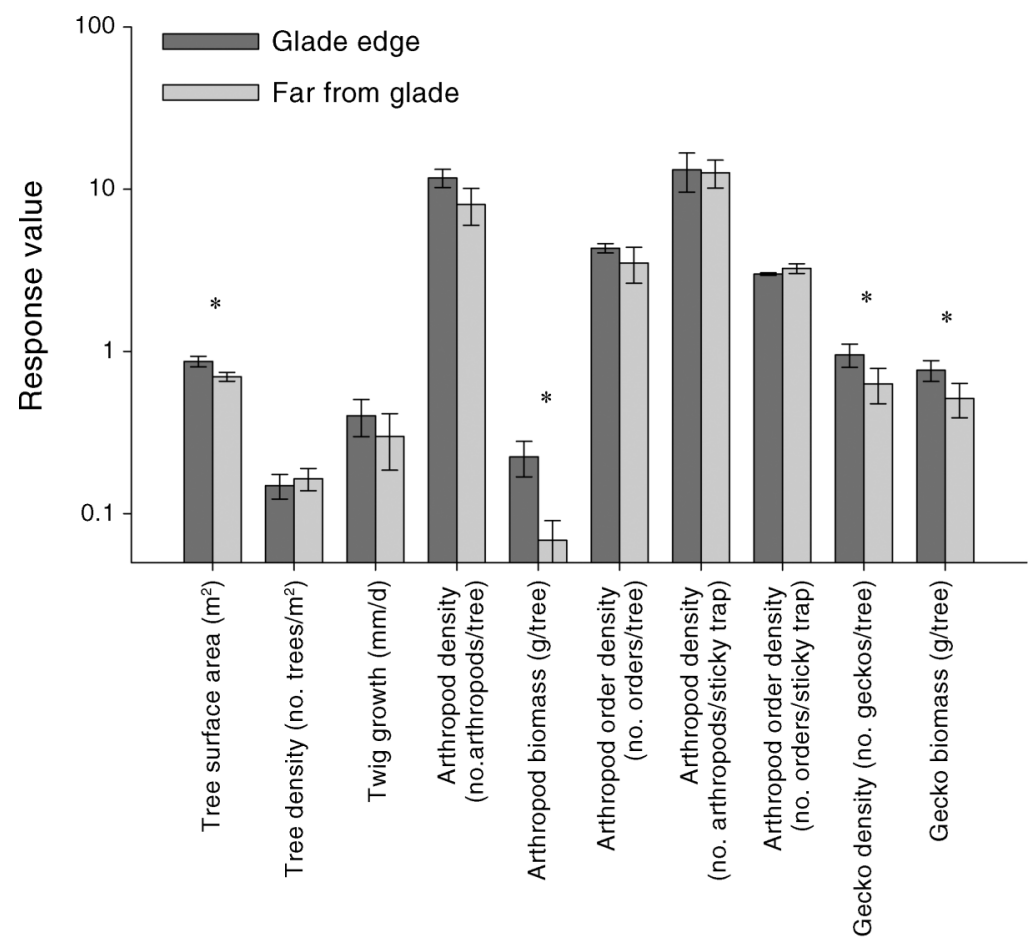

Response variable

FIG. 2. Edge magnitude results for isolated glades. For each response variable, an asterisk $(*)$ indicates the presence of a significant difference between the "glade edge" zone $(<49 \mathrm{~m})$ and the "far-from-glade" zone $(>49 \mathrm{~m})$. Raw mean response values $( \pm \mathrm{SE})$ are plotted on a logarithmic scale.

$* P<0.05$.

vs. $0.63 \pm 0.16$ individuals/tree for abundance, $0.77 \pm$ 0.11 vs. $0.51 \pm 0.12 \mathrm{~g} /$ tree for biomass; for abundance, paired $t=-3.56, P=0.04$; for biomass, paired $t=-3.23$, $P=0.05$; Fig. 2). The relationship between mean per-tree gecko abundance and gecko density per ha (based on a linear regression from data in Pringle et al. 2007) suggests that the observed differences in per-tree abundance should translate into a $\sim 20 \%$ increase in gecko density, from 720 geckos/ha away from glades to 856 geckos/ha in glade edges.

For multiple-glade and cleared-plot transects, the only significant difference between within-edge and far-fromedge zones was for twig growth in cleared plots, which was $>100 \%$ greater far from edges as within them $(0.29$ \pm 0.01 vs. $0.12 \pm 0.03 \mathrm{~mm} / \mathrm{d}$, paired $t=8.24, P=0.01$ ). No other response variable showed significant differences between the $<49-\mathrm{m}$ and $>49-\mathrm{m}$ regions for cleared-plot and multiple-glade transects.

\section{Comparisons across treatments}

Comparing only the initial $49 \mathrm{~m}$ ("edge") zone of each transect, mean tree size did not differ significantly between glade and non-glade transects $\left(F_{1,12}=0.53, P\right.$ $=0.5$; Fig. 3a). However, mean tree density in glade transects was more than double that in non-glade transects $\left(0.13\right.$ vs. 0.06 trees $/ \mathrm{m}^{2} ; F_{1,12}=11.9, P=$ $0.005)$ and was significantly greater in isolated-glade transects $\left(0.15 \pm 0.03\right.$ trees $\left./ \mathrm{m}^{2}\right)$ than in control or cleared-plot transects $(0.07 \pm 0.01$ and $0.05 \pm 0.02$ trees/ $\mathrm{m}^{2}$, respectively; $F_{3,10}=5.3, P=0.02$; Fig. 3b). Similarly, mean twig growth rate in the $<49$-m edge zone was nearly three times greater in glade than non-glade transects $\left(0.32\right.$ vs. $0.11 \mathrm{~mm} / \mathrm{d} ; \log$-transformed $F_{1,12}=$ $6.70 ; P=0.02$; Fig. 3c).

The number of aerial insects caught in sticky traps in the $<49$-m zone did not differ significantly between glade and non-glade transects (log-transformed $F_{1,9}=$ 1.02, $P=0.3)$ or among control, cleared-plot, and isolated-glade transects $\left(F_{2,8}=0.69, P=0.5\right)$. The mean number of aerial arthropod orders was similar between glade and non-glade transects $\left(F_{1,9}=0.52, P=0.5\right)$, but was significantly higher in isolated-glade transects $(3.0 \pm$ $0.05)$ and cleared-plot transects $(3.2 \pm 0.11)$ than in control transects $\left(2.7 \pm 0.11 ; F_{2,8}=8.08, P=0.01\right)$.

Mean per-tree gecko abundance was $70 \%$ higher in glade than in non-glade transects $(0.78$ vs. 0.46 individuals/tree; $F_{1,12}=6.26, P=0.03$; Fig. $3 \mathrm{~d}$ ), and mean pertree gecko biomass was $80 \%$ higher $(0.63$ vs. $0.35 \mathrm{~g} /$ tree; $F_{1,12}=7.90, P=0.02$; Fig. 3e). When we compared glade edge values among all four treatments, we found that 

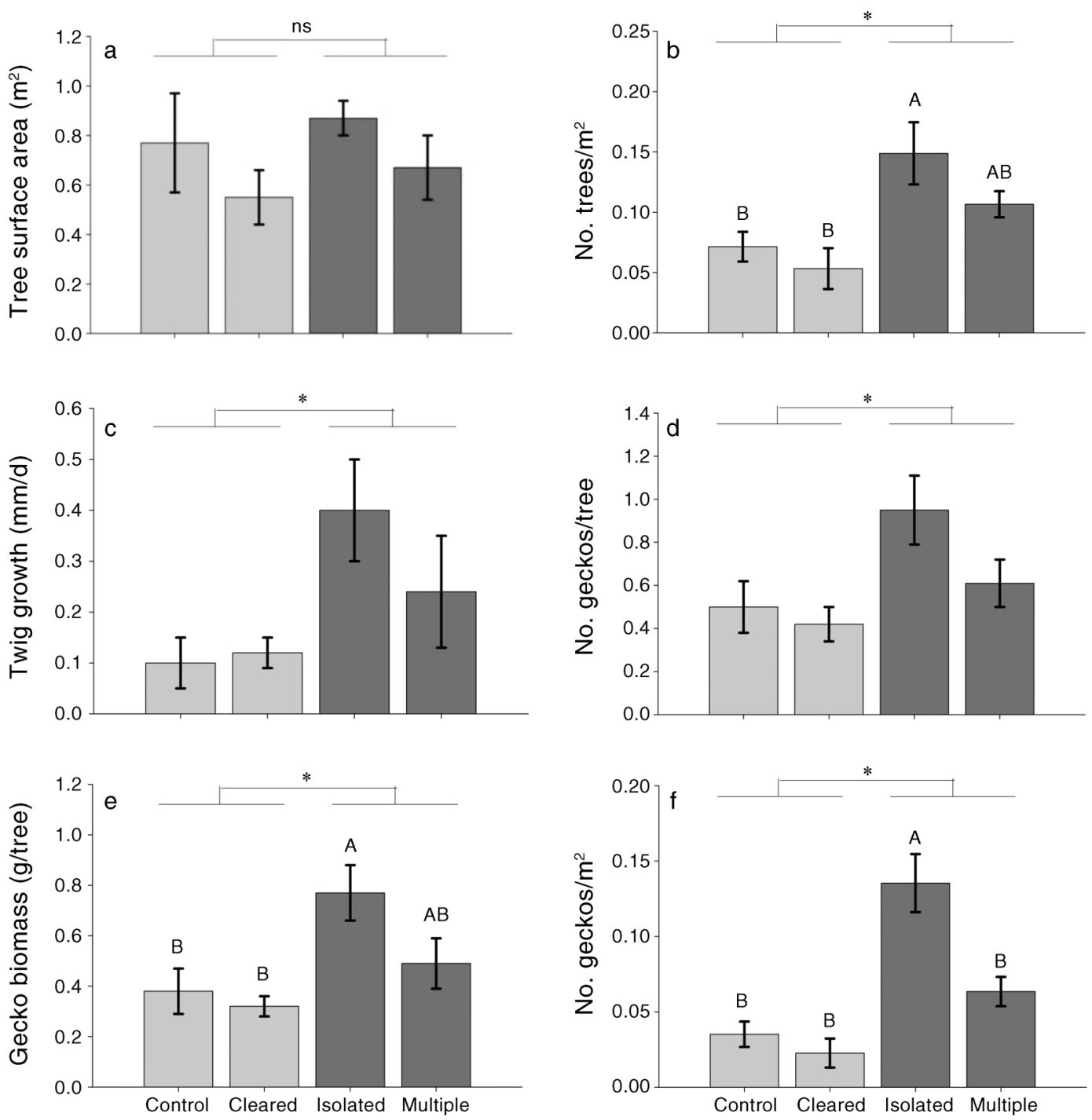

FIG. 3. Treatment effects on (a) tree size, (b) tree density, (c) twig growth rate, (d) per-tree gecko abundance, (e) per-tree gecko biomass, and (f) overall gecko density within the edge zone $(<49 \mathrm{~m})$. Statistical signficance of differences between non-glade transects (light gray) and glade transects (dark gray) is indicated at the top of each panel. Capital letters indicate the presence of significant differences among all four treatments (Tukey's HSD tests). Treatments not sharing a letter are significantly different $(P$ $<0.05)$.

* $P<0.05 ;$ ns, not significant.

biomass of geckos per tree was significantly greater for isolated-glade transects $(0.77 \pm 0.11 \mathrm{~g})$ than for control or cleared-plot transects $(0.38 \pm 0.09$ and $0.32 \pm 0.04$, respectively), whereas multiple-glade transects had intermediate values $\left(0.49 \pm 0.10 \mathrm{~g} ; F_{3,10}=4.6, P=\right.$ 0.03 ; Fig. 3e). Per-tree gecko abundance displayed a similar pattern $\left(F_{3,10}=3.6, P=0.05\right.$; Fig. $\left.3 \mathrm{~d}\right)$, although treatments did not differ significantly using Tukey's HSD post hoc means comparisons.

Because tree densities were also higher in glade transects, effects on minimum gecko density (average number of individuals per survey divided by area) were amplified relative to per-tree results. Minimum gecko density was more than three-times greater in glade $(0.10$ \pm 0.018 individuals $\left./ \mathrm{m}^{2}\right)$ vs. non-glade $(0.030 \pm 0.0063)$ transects (log-transformed $F_{1,12}=19.6, P=0.0008$; Fig. 3f). This result was driven by results from isolated glades, where densities were significantly greater than all other treatments, and $>100 \%$ greater than those in multiple-glade transects $\left(F_{3,10}=14.9, P=0.0005\right.$; Fig. 3$)$. Using the known relationship between average observed number of geckos per survey and density estimated from mark-resight methods $\left(R^{2}=0.83\right.$; see Methods: Data collection), we estimate that the true density of geckos is 0.18 individuals $/ \mathrm{m}^{2}$ near glades, compared with 0.055 in non-glade areas. 
TABLE 2. Ordinal regression models of gecko per-tree abundance patterns and relative importance of each variable.

\begin{tabular}{|c|c|c|c|c|c|c|c|}
\hline \multirow[b]{2}{*}{ Rank } & \multirow[b]{2}{*}{ Model specification } & \multicolumn{4}{|c|}{ Model statistics } & \multirow[b]{2}{*}{ Variable } & \multirow{2}{*}{$\begin{array}{l}\text { Relative } \\
\text { importance }\end{array}$} \\
\hline & & $\mathrm{AIC}_{\mathrm{c}}$ & $K$ & $\Delta_{i}$ & $w_{i}$ & & \\
\hline 1 & sqrt $($ tree size $)+\log ($ glade $)+$ mound + & 1217.31 & 5 & 0.00 & 0.449 & tree size & 1.00 \\
\hline 2 & sqrt $($ tree size $)+\log ($ glade $)+$ mound + ant + block & 1217.93 & 6 & 0.62 & 0.337 & distance from glade & 0.99 \\
\hline 3 & sqrt(tree size $)+\log ($ glade $)+$ mound + block & 1220.16 & 5 & 2.85 & 0.108 & distance from mound & 0.97 \\
\hline 4 & sqrt $($ tree size $)+\log ($ glade $)+$ mound & 1221.06 & 4 & 3.75 & 0.068 & ant sp. & 0.82 \\
\hline 32 & constant only & 1410.12 & 1 & 192.81 & 0.000 & block & 0.46 \\
\hline
\end{tabular}

Note: Coefficients in the top-ranked model were 3.72 for sqrt(tree size) (where sqrt stands for square root), -0.20 for log(glade), -0.15 for mound, and 0.14 for ant; the four intercepts were $1.02(0 \mid 1), 3.77(1 \mid 2), 5.90(2 \mid 3)$, and $6.94(3 \mid 4)$.

When we compared values in the "far-from-glade" ( $>49 \mathrm{~m}$ ) zone of each transect, we found no significant differences among treatments for any response variable.

\section{Modeling per-tree gecko abundance}

Only two of the 32 candidate ordinal regression models of per-tree gecko abundance had substantial empirical support $\left(\Delta_{i}<2\right.$; Burnham and Anderson 2010); these differed only in the inclusion of a block effect, with a combined Akaike weight $w=0.79$. The third- and fourth-ranking models, which also differed only in the inclusion of block, had a combined $w=0.18$ (Table 2, under "Model statistics"). Together, the four best models came close to rounding out a $95 \%$ set, and differed only in their inclusion of block and resident ant species, two variables ancillary to our hypotheses. Quantifying the relative importance of different variables further emphasized that tree size, glade proximity, and termite mound proximity were all key predictors of per-tree gecko abundance, whereas the ant and block terms appeared relatively unimportant (Table 2 , under relative importance). Coefficients of the best-fitting model showed that per-tree gecko abundance increased as a function of tree size, decreased with increasing distance from glades and termite mounds, and was greatest on trees inhabited by the least-aggressive ant, Crematogaster sjostedti (Table 2; see also Palmer and Brody 2007).

There was an excellent fit between model predictions and the original data used to parameterize the model $\left(r^{2}\right.$ $=0.78$, slope $\approx 1$; Fig. 4). When the same model (with identical coefficients) was applied to a novel dataset collected nine months after the original data, the correlation between predicted and observed values was very strong $\left(r^{2}=0.75\right)$, although the slope (1.7) differed significantly from $1(t=2.99, \mathrm{df}=18, P=0.008$; Fig. 4$)$.

\section{Discussion}

Isolated glades had pronounced edge effects on the growth rates and size structure of trees, as well as on the biomass distribution of arboreal arthropods and geckos (Figs. 1-3). We conclude that glades (legacies of traditional range management practices) create largescale spatial heterogeneity across multiple trophic levels in a system that is otherwise remarkably uniform in topography and species composition (Young et al. 1998). These effects of glades contrast with those of overgrazing (the more commonly reported legacy of rangeland management), which tends to homogenize vegetation structure and has the potential to tip entire landscapes toward simplified (and even desertified) alternative states (Asner et al. 2004).

\section{High productivity associated with glades propagates to higher trophic levels}

We propose that the fertilization effect of glades leaks outward via both abiotic (e.g., leaching) and biotic (e.g., elevated ungulate use) mechanisms, elevating growth rates and foliar nutrient concentrations in trees near glades. In turn, elevated forage quantity and quality increases local densities of arboreal arthropods and

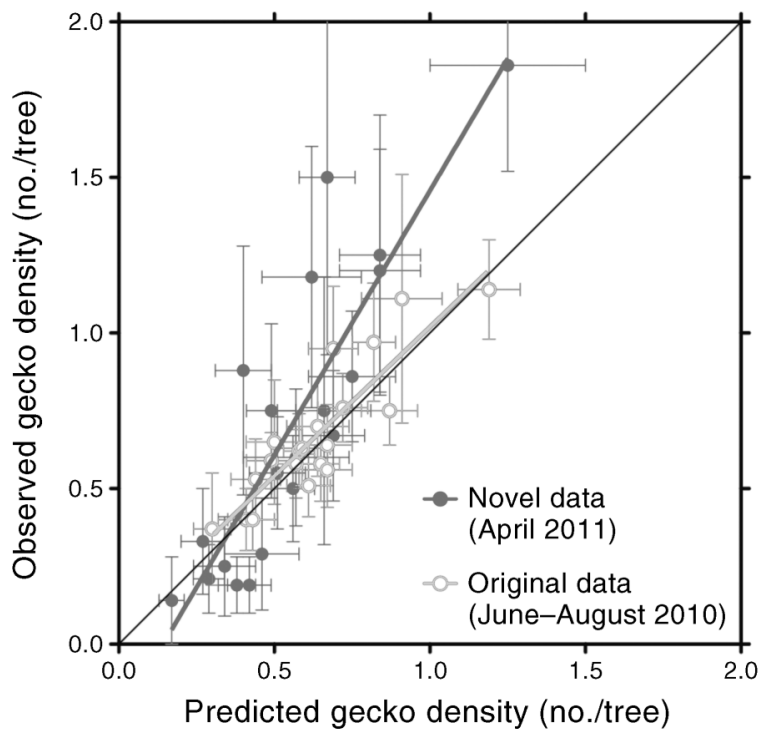

FIG. 4. Tests of fit and predictive power of our highestranking ordinal regression model for gecko per-tree abundance (Table 2). Data were pooled and grouped according to glade proximity (20 5-m bins); points show means \pm SE for each bin. Open circles show the original data used to parameterize the model; solid circles show novel data used to test the model. Light and dark gray lines show ordinary least-squares (OLS) regressions for original and novel data, respectively; black 1:1 line, indicating perfect fit, is plotted for reference. 
insectivores. This effect attenuates with distance at different rates for different taxa (Fig. 1), dissipating fastest among sessile trees and more slowly among mobile consumers, whose foraging radii may include trees both inside and outside the zone of glade influence. Available data support this interpretation. Soil concentrations of multiple nutrients decline steeply at glade edges, but remain higher than background levels up to 50-100 m away (Young et al. 1995). Elevated soil nutrients likely translate to higher $A$. drepanolobium foliar nutrient concentrations, as has been found around termite mounds in this ecosystem (Fox-Dobbs et al. 2010).

Ordinal regression modeling showed that proximity to glades (along with several other previously identified factors) was an important determinant of per-tree gecko abundance patterns. This model provided an excellent fit to the data and a strong correlation with a novel dataset collected to test the model, suggesting that the model parameters were robust (Fig. 4).

The covariation of tree size with glade proximity means that a non-trophic effect of glades on habitat structure likely contributed to the observed glade edge effects on gecko abundance and biomass. However, multiple additional lines of evidence indicate that tree size structure alone cannot explain the observed patterns. First, glade proximity had a relative importance of 0.99 in the analysis of AIC values (Table 2), indicating that this variable was both necessary to explain patterns of per-tree gecko abundance and was not redundant with other predictors. Second, edge depth for tree size was less than that for geckos (Fig. 1): The effect on geckos persisted even after the effect on tree size had dissipated. Third, mean tree size in control transects was relatively large $\left(0.77 \pm 0.20 \mathrm{~m}^{2}\right)$ and not significantly different from that in the edge zone of glade transects $\left(0.87 \pm 0.07\right.$ and $0.67 \pm 0.13 \mathrm{~m}^{2}$ for isolated and multiple glades, respectively), whereas this was not true for gecko abundance or biomass (Fig. 3). Finally, previous experiments in this system have shown that gecko abundance effectively tracks local prey availability (Pringle et al. 2010). It therefore seems clear that glade-induced heterogeneity in prey availability induces at least an aggregational behavioral response among geckos, although we lack the data necessary to estimate how great a change in prey density is necessary to induce such a response. Likewise, further experiments will be required to determine whether geckos also exhibit a numerical response to glades, but we consider it likely: Elevated quantity and quality of tree forage should improve provisioning of insect herbivores and their predators, thereby increasing reproductive rates and/or offspring survival (Doughty and Shine 1998, Hemmi and Jormalainen 2002). In this system, for example, the fecundity of web spiders decreases with distance from nutrient-rich termite mounds (Pringle et al. 2010).

"Upwardly cascading" effects of nutrient enrichment, similar to those induced by isolated glades in this study, have been documented in other systems (Hunter and Price 1992, Kagata and Ohgushi 2005). Elsewhere in Kenya, Söderström and Reid (2010) documented elevated abundances of insects and birds within $200 \mathrm{~m}$ of abandoned pastoral settlements. In Hawaii, experimental fertilization increased growth rates and foliar $\mathrm{N}$ concentrations of the tree Metrosideros polymorpha, increasing the density and biomass of herbivorous insects and spiders (Gruner 2004). Similarly, experimental enrichment of a temperate old-field food web increased primary productivity and biomass of plants and herbivores (Schmitz 1994).

\section{Glade edge effects are driven by nutrient inputs}

As predicted, experimentally cleared glade-sized plots did not induce effects similar to those of isolated glades: Response values such as tree growth and gecko density in cleared-plot edges were similar to or even lower than those in control transects (Fig. 3). As in glades, herbaceous primary productivity and herbivore utilization in cleared plots were elevated relative to background levels (C. Riginos, unpublished manuscript). The lack of edge effects around experimentally cleared plots therefore suggests that legacies of historical nutrient loading are responsible for elevated woody growth rates and consumer biomass in glade edges. One exception to this general pattern was the order-level diversity of aerial arthropods, which was greater in glade and cleared-plot transects than in control transects. The lack of a response to glades by flying insects, coupled with the strong effects of glades on pre-tree arboreal arthropod abundance (Fig. 2), suggests that highly mobile consumers can forage over broad areas and should therefore be less constrained by local resource availability than the crawling and weakly flying insects that inhabit Acacia canopies. These results may also stem in part from our sampling methods, particularly the use of sticky traps, which are known to imperfectly sample aerial arthropods (Cooper and Whitmore 1990).

\section{Glade edge interactions dampen edge effects on consumer abundance}

Whereas the effects of isolated glades were pronounced, those between multiple glades were weak (Table 1, Fig. 1) and not significantly different from background (Fig. 3). That is, edge effects between multiple glades are less than the sum of their parts. This counterintuitive outcome contrasts with the naïve prediction that effect size should be an increasing function of glade density, but is consistent with recent work on interacting edge effects in this system. Porensky (2011) showed that when compared to isolated-glade edges, areas between nearby glades have relatively low densities of large trees $(>4 \mathrm{~m}$ tall) and relatively high densities of small trees $(<2 \mathrm{~m}$ tall). These results provide one explanation for the reduced per-tree abundance of geckos between glades; trees $<2 \mathrm{~m}$ tall are rarely inhabited by geckos ( $95 \%$ confidence range in our study, 
0.18-0.28 individuals), whereas trees $>4 \mathrm{~m}$ tall almost always support at least one individual (0.99-1.39 individuals). Furthermore, the high densities of short, scrubby trees between adjacent glades reduces use of these areas by native ungulates (Porensky 2011), which in turn, likely reduces nutrient inputs relative to isolatedglade edges or even background savanna. We expect trees between adjacent glades to remain small for at least the life span of the glades themselves due to slow tree growth rates, high tree densities, and low nutrient inputs in these areas. Thus, despite ample initial fertilization, the bottom-up cascade effect does not strongly affect higher trophic levels in areas between multiple nearby glades.

Land managers in Africa increasingly seek to manage private lands for multiple uses, including livestock production, biodiversity conservation, and ecotourism, and some managers are interested in strategically locating new glades to advance those objectives (G. Prettejohn, Ol Pejeta Conservancy, personal commumication). Our findings show both that glades impart spatial structure across multiple levels of a food web, and also that these effects are contingent on glade density and spatial configuration. A recent study from this system showed that the uniform spatial patterning of Odontotermes termite mounds, which have cascading influences similar to those of glades, increases production and biomass across multiple trophic levels relative to simulated landscapes with nonuniform mound distributions (Pringle et al. 2010). This suggests that the ecological impacts of glades on savanna communities would be maximized by placing them in a uniform lattice pattern. A definitive experimental test of this proposition using termite mounds would be difficult because it is impossible to manipulate mound location (Schmitz 2010). Glades, however, can be created in predetermined spatial arrangements, raising the possibility of a direct experimental test of how uniform spatial patterning of nutrient hotspots influences production and biomass at a broad scale.

\section{ACKNOWLEDGMENTS}

We thank the Government of Kenya for permission to conduct this work and the Mpala Research Centre for logistical support. Funding was provided by NSF OISE-0852961 to R. M. Pringle; by the University of Michigan to C. M. Donihue; by an NSF Graduate Research Fellowship, NSF DES 08-16453 through T. P. Young, and the UC-Davis Plant Sciences Fellowship to L. M. Porensky; and an NSF Doctoral Dissertation Improvement Grant to C. Riginos. Finally, we thank Oswald Schmitz and two anonymous reviewers for useful comments on drafts of the manuscript.

\section{Literature Cited}

Ahn, P. M., and L. C. Geiger. 1987. Soils of Laikipia District. National Agricultural Research Laboratories, Nairobi, Kenya.

Asner, G. P., A. R. Townsend, M. M. C. Bustamante, G. B. Nardoto, and L. P. Olander. 2004. Pasture degradation in the central Amazon: linking changes in carbon and nutrient cycling with remote sensing. Global Change Biology 10:844862.
Augustine, D. J., and S. J. McNaughton. 2004a. Temporal asynchrony in soil nutrient dynamics and plant production in a semiarid ecosystem. Ecosystems 7:829-840.

Augustine, D. J., and S. J. McNaughton. 2004b. Regulation of shrub dynamics by native browsing ungulates on East African rangeland. Journal of Applied Ecology 41:45-48.

Burnham, K. P., and D. R. Anderson. 2010. Model selection and multi-model inference: a practical information-theoretic approach. Springer, New York, New York, USA.

Cooper, R. J., and R. C. Whitmore. 1990. Arthropod sampling methods in ornithology. Studies in Avian Biology 13:29-37.

Doughty, P., and R. Shine. 1998. Reproductive energy allocation and long-term energy stores in a viviparous lizard (Eulamprus tympanum). Ecology 79:1073-1083.

Dwyer, J. M., R. J. Fensham, and Y. M. Buckley. 2010. Agricultural legacy, climate, and soil influence the restoration and carbon potential of woody regrowth in Australia. Ecological Applications 20:1838-1850.

Elgersma, K. J., J. G. Ehrenfeld, S. Yu, and T. Vor. 2011. Legacy effects overwhelm the short-term effects of exotic plant invasion and restoration on soil microbial community structure, enzyme activities, and nitrogen cycling. Oecologia 167:733-745.

Figueroa-Rangel, B. L., K. J. Willis, and M. Olvera-Vargas. 2008. 4200 years of pine-dominated upland forest dynamics in west-central Mexico: Human or natural legacy? Ecology 89:1893-1907.

Foster, D., F. Swanson, J. Aber, I. Burke, N. Brokaw, D. Tilman, and A. Knapp. 2003. The importance of land-use legacies to ecology and conservation. Bioscience 53:77-88.

Fox-Dobbs, K., D. F. Doak, A. K. Brody, and T. M. Palmer. 2010. Termites create spatial structure and govern ecosystem function by affecting $\mathrm{N}_{2}$ fixation in an East African savanna. Ecology 91:1296-1307.

Friedman, S. K., and P. B. Reich. 2005. Regional legacies of logging: departure from presettlement forest conditions in northern Minnesota. Ecological Applications 15:726-744.

Goheen, J. R., and T. M. Palmer. 2010. Defensive plant-ant stabilize megaherbivore-driven landscape change in an African savanna. Current Biology 20:1768-1772.

Greer, A. E. 1967. The ecology and behavior of two sympatric Lygodactylus geckos. Brevoria 268:1-16.

Gruner, D. S. 2004. Attenuation of top-down and bottom-up forces in a complex terrestrial community. Ecology 85:30103022.

Hemmi, A., and V. Jormalainen. 2002. Nutrient enhancement increases performance of a marine herbivore via quality of its food alga. Ecology 83:1052-1064.

Hunter, M. D., and P. W. Price. 1992. Playing chutes and ladders: heterogeneity and the relative roles of bottom-up and top-down forces in natural communities. Ecology 73:724-732.

Huntzinger, M., R. Karban, and J. L. Maron. 2011. Small mammals cause non-trophic effects on habitat and associated snails in a native system. Oecologia 167:1085-1091.

Kagata, H., and T. Ohgushi. 2006. Bottom-up trophic cascades and material transfer in terrestrial food webs. Ecological Research 21:26-34.

Kuria, S. K. 2006. The role of ants in structuring insect communities on the canopies of Senegalia drepanolobium near Laikipia, Kenya. Dissertation. Rhodes University, Grahamstown, South Africa.

Kuria, S. K., M. H. Villet, T. M. Palmer, and M. L. Stanton. 2010. A comparison of two sampling methods for surveying mammalian herbivore impacts on beetle communities in the canopy of Acacia drepanolobium in Kenya. African Entomology 18:87-98.

Lamprey, R., and R. S. Reid. 2004. Expansion of human settlement in Kenya's Maasai Mara: what future for pastoralism and wildlife? Journal of Biogeography 31:9971032. 
Ledger, M. E., R. M. L. Harris, A. M. Milner, and P. D. Armitage. 2006. Disturbance, biological legacies and community development in stream mesocosms. Oecologia 148:682-691.

Liu, J., et al. 2007. Complexity of coupled human and natural systems. Science 317:1513-1516.

McKey, D., S. Rostain, J. Iriarte, B. Glasser, J. J. Birk, I. Holst, and D. Renard. 2010. Pre-Columbian agricultural landscapes, ecosystem engineers, and self-organized patchiness in Amazonia. Proceedings of the National Academy of Sciences USA 107:7823-7828.

Muchiru, A. N., D. Western, and R. S. Reid. 2009. The impact of abandoned pastoral settlements on plant and nutrient succession in an African savanna ecosystem. Journal of Arid Environments 73:322-331.

Nuttle, T., E. H. Yerger, S. H. Stoleson, and T. E. Ristau. 2011. Legacy of top-down herbivore pressure ricochets back up multiple trophic levels in forest canopies over 30 years. Ecosphere 2:1-11.

Palmer, T. M., and A. K. Brody. 2007. Mutualism as reciprocal exploitation: African plant-ants defend foliar but not reproductive structures. Ecology 88:3004-3011.

Palmer, T. M., D. F. Doak, M. L. Stanton, J. L. Bronstein, E. T. Kiers, T. P. Young, J. R. Goheen, and R. M. Pringle. 2010. Synergy of multiple partners, including freeloaders, increases host fitness in a multispecies mutualism. Proceedings of the National Academy of Sciences USA 107:1723417239.

Palmer, T. M., M. L. Stanton, T. P. Young, J. R. Goheen, R. M. Pringle, and R. Karban. 2008. Breakdown of an antplant mutualism follows the loss of large herbivores from an African Savanna. Science 319:192-195.

Porensky, L. M. 2011. When edges meet: interacting edge effects in an African savanna. Journal of Ecology 99:923934.

Porensky, L. M., and K. E. Veblen. 2012. Grasses and browsers reinforce landscape heterogeneity by excluding trees from ecosystem hotspots. Oecologia 168:749-759.

Pringle, R. M. 2008. Elephants as agents of habitat creation for small vertebrates at the patch scale. Ecology 89:26-33.

Pringle, R. M., D. F. Doak, A. K. Brody, R. Jocqué, and T. M. Palmer. 2010. Spatial pattern enhances ecosystem functioning in an African savanna. PLoS Biology 8:1-12.

Pringle, R. M., and K. Fox-Dobbs. 2008. Coupling of canopy and understory food webs by ground-dwelling predators. Ecology Letters 11:1328-1337.

Pringle, R. M., T. P. Young, D. I. Rubenstein, and D. J. McCauley. 2007. Herbivore-initiated interaction cascades and their modulation by productivity in an African savanna.
Proceedings of the National Academy of Sciences USA 104:193-197.

Riginos, C., and J. B. Grace. 2008. Acacia tree density, wild ungulate habitat use, and the herbaceous community in a Kenyan savanna: bottom-up vs. top-down effects. Ecology 89:2228-2238.

Rowe, R. J. 2007. Legacies of land use and recent climatic change: The small mammal fauna in the mountains of Utah. American Naturalist 170:242-257.

SAS Institute. 2009. JMP version 8.0. SAS Institute, Cary, North Carolina, USA.

Schmitz, O. J. 1994. Resource edibility and trophic exploitation in an old-field food web. Proceedings of the National Academy of Sciences USA 91:5364-5367.

Schmitz, O. J. 2010. Spatial dynamics and ecosystem functioning. PLoS Biology 8:1-3.

Sharp, B. R., and R. J. Whittaker. 2003. The irreversible cattledriven transformation of a seasonally flooded Australian savanna. Journal of Biogeography 30:783-802.

Söderström, B., and R. S. Reid. 2010. Abandoned pastoral settlements provide concentrations of resources for savanna birds. Acta Oecologica 36:184-190.

Valone, T. J., M. Meyer, J. H. Brown, and R. M. Chew. 2002. Timescale of perennial grass recovery in desertified arid grasslands following livestock removal. Conservation Biology 16:995-1002.

Veblen, K. E. 2008. Season- and herbivore-dependent competition and facilitation in a semiarid savanna. Ecology 89:1532-1540.

Veblen, K. E. 2012. Savanna glade hotspots: Plant community development and synergy with large herbivores. Journal of arid Environments 78:119-127.

Veblen, K. E., and T. P. Young. 2010. Contrasting effects of cattle and wildlife on the vegetation development of a savanna landscape mosaic. Journal of Ecology 98:993-1001.

Western, D., and T. Dunne. 1979. Environmental aspects of settlement site decisions among pastoral Maasai. Human Ecology 7:75-98.

Young, T. P., B. D. Okello, D. Kinyua, and T. M. Palmer. 1998. KLEE: A long-term multi-species herbivore exclusion experiment in Laikipia, Kenya. African Journal of Range and Forage Science 14:94-102.

Young, T. P., N. Patridge, and A. Macrae. 1995. Long-term glades in Acacia bushland and their edge effects in Laikipia, Kenya. Ecological Applications 5:97-108.

Young, T. P., C. H. Stubblefield, and L. A. Isabell. 1997. Ants on swollen-thorn acacias: species coexistence in a simple system. Oecologia 109:98-107. 